\title{
CORRIGENDUM
}

\section{The hydrodeoxygenation of bioderived furans into alkanes}

Andrew D. Sutton, Fraser D. Waldie, Ruilian Wu, Marcel Schlaf, Louis A. 'Pete' Silks III and John C. Gordon

Nature Chemistry 5, 428-432 (2013); published online 7 April 2013; corrected after print 26 April 2013.

In the version of this Article originally published, the reaction conditions given in Fig. 3 for conversion of compound 2 to compound 4 were incorrect, and should have been stated as 'Acetic acid/ $\mathrm{H}_{2} \mathrm{O}, 100^{\circ} \mathrm{C}, 3 \mathrm{~h}$ '; this has now been corrected in the HTML and PDF versions of this Article.

\section{CORRIGENDUM}

\section{The hydrodeoxygenation of bioderived furans into alkanes}

Andrew D. Sutton, Fraser D. Waldie, Ruilian Wu, Marcel Schlaf, Louis A. 'Pete' Silks III and John C. Gordon

Nature Chemistry 5, 428-432 (2013); published online 7 April 2013; corrected after print 26 April 2013 and 2 May 2013.

In the version of this Article originally published, references to certain compound numbers in the Methods section were incorrect: Under the heading 'General experimental' “...conversion of $\mathbf{3}$ into $n$-nonane..." should have read “...conversion of $\mathbf{2}$ into $n$-nonane...”. In 'Conversion of A into 2,5,8-nonanetrione 4, “... solvent removed in vacuo to yield 3..." should have read "... solvent removed in vacuo to yield 4...”. In 'Conversion of B into 2,5,8-nonanetrione 4, “... solvent removed in vacuo to yield 3...” should have read "... solvent removed in vacuo to yield 4...” These errors have been corrected in the HTML and PDF versions of the Article. 